\title{
BMJ Open Perceived barriers and facilitators to chronic kidney disease care among patients in Singapore: a qualitative study
}

\author{
Sun Joon Hwang, ${ }^{1}$ Ngiap Chuan Tan (D) , ${ }^{2,3}$ Sungwon Yoon, ${ }^{1}$ \\ Chandrika Ramakrishnan, ${ }^{1}$ Muthulakshmi Paulpandi, ${ }^{2}$ Shihying Gun, ${ }^{3}$ Jia Ying Lee, ${ }^{3}$ \\ Zi Ying Chang, ${ }^{3}$ Tazeen H Jafar (D) ${ }^{1,4}$
}

To cite: Hwang SJ, Tan NC, Yoon S, et al. Perceived barriers and facilitators to chronic kidney disease care among patients in Singapore: a qualitative study. BMJ Open 2020;10:e041788. doi:10.1136/ bmjopen-2020-041788

- Prepublication history and additional material for this paper are available online. To view these files, please visit the journal online (http://dx.doi. org/10.1136/bmjopen-2020041788).

Received 17 June 2020 Revised 11 August 2020 Accepted 16 September 2020

A) Check for updates

(C) Author(s) (or their employer(s)) 2020. Re-use permitted under CC BY-NC. No commercial re-use. See rights and permissions. Published by BMJ.

${ }^{1}$ Program in Health Services \& Systems Research, Duke-NUS Medical School, Singapore ${ }^{2}$ Department of Research, SingHealth Polyclinics, Singapore

${ }^{3}$ General Practice, SingHealth Polyclinics, Singapore ${ }^{4}$ Department of Renal Medicine, Singapore General Hospital, Singapore

Correspondence to

Dr Tazeen H Jafar:

tazeen.jafar@duke-nus.edu.sg

\section{ABSTRACT}

Objective To outline the facilitators and barriers to patients' self-management of predialysis chronic kidney disease (CKD).

Design Qualitative.

Setting Three polyclinics in a public primary care institution in Singapore.

Participants 20 patients entered and completed the study. Inclusion criteria were: (1) English speaking, (2) aged 40 years and above, (3) identified by clinical coding as 'DM (diabetes mellitus) nephropathy-overt' and 'DM nephropathy-incipient', by their physicians in the polyclinic, with an estimated glomerular filtration rate of less than $60 \mathrm{~mL} / \mathrm{min} / 1.73 \mathrm{~m}^{2}$ (based on electronic health records) and (4) aware of their CKD illness. Exclusion criteria were: (1) receiving dialysis or had received a kidney transplant, (2) suffered from any visual, auditory or cognitive impairment which could hinder their ability to participate in the study or (3) pregnant.

Results We found that the major barriers to CKD management were a lack of knowledge and awareness of CKD, a passive attitude toward self-management and insufficient patient-physician communication. Major facilitators included patient trust and satisfaction with the physician and family support. Many patients reported that there was an overload of information and too little guidance on how to manage their condition, especially regarding dietary recommendations.

Conclusion We identified several barriers and facilitators to the management of predialysis CKD among patients. A multi-pronged approach for raising CKD awareness is required: improving patient-physician communication, implementing CKD workshops and home-visits and disseminating accurate online information about CKD. Strategies should also focus on increasing patient engagement and optimising family support by involving family members in patients' care. Furthermore, clear dietary recommendations and patient-specific advice are needed to empower patients to manage their own condition.

\section{INTRODUCTION}

Chronic kidney disease (CKD), defined as the presence of kidney damage or decreased
Strengths and limitations of this study

- Both inductive and deductive methods used to capture all key themes.

- Robust conceptual framework to organise findings.

- Only English-speaking patients were recruited.

- Due to multicultural background of patients, cultural references may have been lost in the analysis.

kidney function for three or more months, has become one of the most rapidly rising causes of death globally, including in Singapore. ${ }^{1}$ CKD is associated with an increased risk of cardiovascular disease and premature mortality rates. ${ }^{2}$ If CKD is not treated and monitored, it may also progress to endstage kidney disease (ESKD), which requires expensive renal replacement therapy (RRT) and is associated with a poor quality of life. ${ }^{3}$ ESKD is a significant burden economically, as annual healthcare costs for patients on RRT are substantially higher than that for CKD patients. $^{4}$

Singapore is ranked first in the world for diabetes-induced ESKD and has the fourth highest prevalence of ESKD in the world. ${ }^{5}$ Moreover, the incidence rate of CKD stage 5 (which includes ESKD) in Singapore rose from 347.8 per million population ( $\mathrm{pmp}$ ) in 2008 to $480 \mathrm{pmp}$ in $2016 .{ }^{6}$ Significant risk factors for CKD include diabetes and hypertension, which are on the rise in Singapore, along with its ageing population. Early identification and prudent management of these risk factors via lifestyle modification and pharmacological management can significantly slow the progression of CKD as well as reduce mortality and morbidity rates. ${ }^{7}$

Along with risk factor modification, preventing CKD progression requires a thorough understanding of the impediments to 
effective CKD management. ${ }^{7}$ Moreover, CKD comes with numerous challenges and requires diligent cooperation from patients for effective management of the disease. ${ }^{8}$ Despite this need, treatment adherence in CKD patients tends to be poor due to a lack of awareness of CKD and low overall health literacy. ${ }^{7}{ }^{10}$ Information currently available for patients include continuous medical education sessions and health promotion activities that take place at primary care clinics, but these tend to focus on diabetes and not specifically CKD. Existing initiatives in Singapore for CKD focus on assisting physicians, but they do little to address patients' challenges to management. Understanding CKD management and its challenges from the patients' perspective will be vital in developing patient-centred interventions which will improve patients' behaviour with respect to treatment adherence, thereby leading to better patient outcomes.

Most studies on CKD management have been conducted in the West, and little is known about the obstacles to CKD management in Singapore. A recent study in rural India found that a lack of awareness and a shortage of health resources to be barriers to CKD care. ${ }^{11}$ Previous studies also suggest that a key difference in CKD management in the West and in Singapore is the centrality of family support. ${ }^{12} 13$ One study in Singapore explored the barriers and facilitators to ESKD management (ie, dialysis and kidney transplant) and found that family and peer support enhance self-management, ${ }^{12}$ but no other study in Singapore has identified the barriers and facilitators to predialysis CKD management from the patients' perspectives. The focus on earlier CKD stages is essential. Since the goal is to prevent CKD progression, it will be crucial to identify and address gaps early in CKD management before reaching ESKD.

This study aims to outline the facilitators and barriers to patients' self-management of predialysis CKD in order to find the gaps in CKD care in Singapore. Self-management in the context of chronic disease is defined as 'the ability of the individual, in conjunction with family, community, and healthcare professionals, to manage symptoms, treatments, lifestyle changes, and psychosocial, cultural, and spiritual consequences of health conditions. ${ }^{14}$ Selfmanagement has shown to be a key indicator of the effective management of chronic diseases, especially in patients with earlier stages of CKD. ${ }^{815}$ Furthermore, qualitative studies have been shown to be particularly effective in uncovering patients' perspectives and drawing out their ideas, concerns and beliefs. ${ }^{16}$

\section{METHODS}

We used a qualitative method to conduct one-to-one interviews with patients using a semi-structured question guide. The Consolidated Criteria for Reporting Qualitative Research (COREQ) was used as a reporting framework for this study (online supplemental file 1).

\section{Conceptual framework}

We used the social-ecological model (SEM) as a conceptual framework to guide in the analysis (figure 1). ${ }^{17}$ Widely accepted and used by organisations such as WHO and the Centers for Disease Control and Prevention, the SEM outlines the various factors (individual, interpersonal, community, societal) that interact and contribute to patients' health behaviours. SEM has been adopted as a framework for multiple qualitative studies in various countries and has been found to be especially useful in exploring the motivations behind patient behaviours. ${ }^{18-20}$ There were three main reasons why we selected this model: first, it provides a nuanced view of the determinants of health behaviour. Instead of oversimplifying the matter, the model succinctly captures the various forces that contribute to patients' health behaviour. Second, the model implies that interventions must address multiple

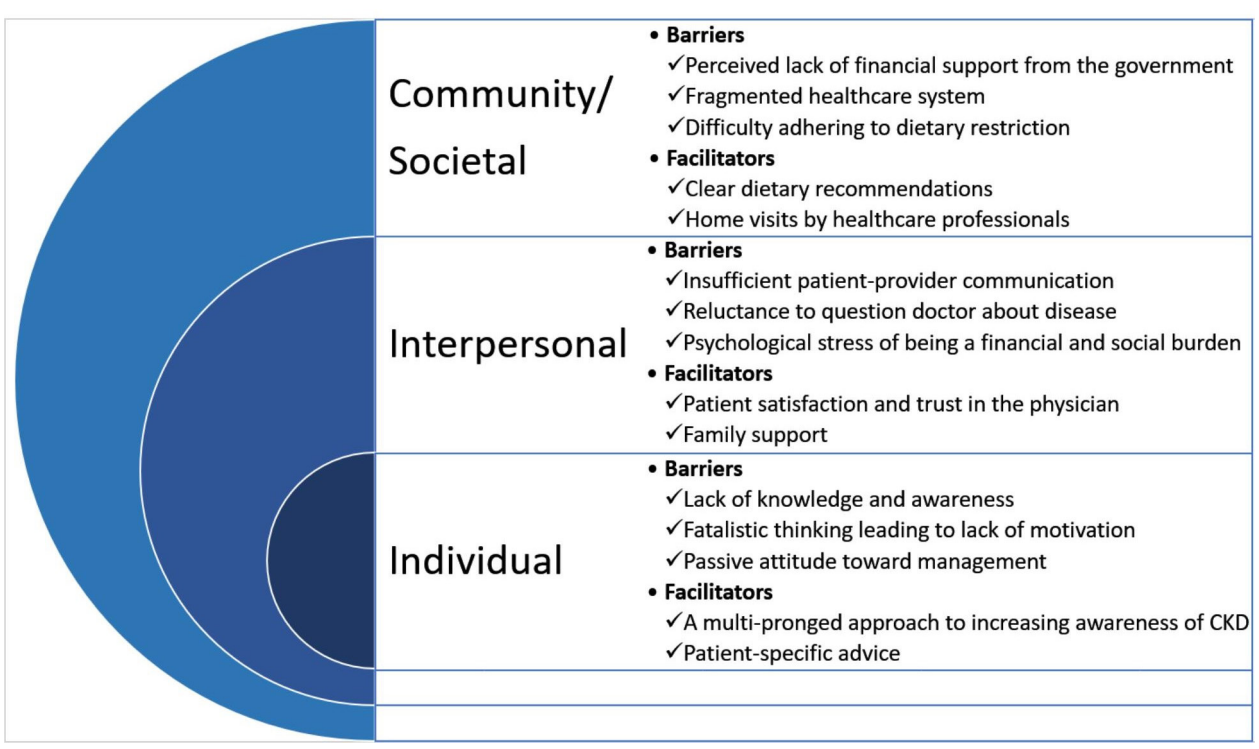

Figure 1 Conceptual framework; modified 3-tier social-ecological model. CKD, chronic kidney disease. 
levels at the same time in order to achieve sustainable success in preventing the progression of CKD to ESKD. This is especially true in an Asian context such as Singapore, where the individual is often not seen as an independent unit but as a part of the larger context of the family and society. Finally, it aligns with our primary objective to explore the patients' experiences regarding the facilitators and barriers to effective CKD management.

\section{Sampling and inclusion criteria}

Patients were recruited from three SingHealth Polyclinics located in Bedok, Sengkang, and Marine Parade estates in eastern Singapore. These primary care clinics are led by family physicians and serve a geographically, socioeconomically and ethnically diverse population. Hypertension, dyslipidaemia and type 2 diabetes mellitus account for the top five conditions managed at these polyclinics. A purposive sampling approach was used to recruit patients in order to ensure adequate representation of gender and age. Patients were eligible to participate if they were (1) English speaking, (2) aged 40 years and above, (3) identified by clinical coding as 'DM (diabetes mellitus) nephropathy-overt' and 'DM nephropathy-incipient', by their physicians in the polyclinic, with an estimated glomerular filtration rate (eGFR) of less than $60 \mathrm{~mL} /$ $\min / 1.73 \mathrm{~m}^{2}$ (based on electronic health records) and (4) aware of their CKD illness (determined by a screening questionnaire, described below). Patients were excluded if they (1) were receiving dialysis or had received a kidney transplant, (2) suffered from any visual, auditory or cognitive impairment which could hinder their ability to participate in the study or (3) were pregnant.

\section{Patient recruitment}

Patients were recruited from June 2018 to June 2019. Preliminarily screening for patients based on eGFR was conducted by the clinical research coordinator and primary physicians, using the electronic health records system. Potential patients were then approached and determined for eligibility. Patients were recruited in two ways. (1) They were recruited in-person by the study team when they came for their prospective regular clinic visits. (2) The primary physician identified a potential patient who qualified for the study, obtained permission from the patient to contact him or her and the study team contacted the patient to confirm their willingness to participate in the study. Additionally, in order to identify patients who are aware of their CKD diagnosis, a brief screening questionnaire was administered. If the eligible patient agreed to participate, written consent was obtained. The written consent included a description of the research study and its goals. The recruited patients were subsequently invited to the study site for the interviews.

In total, 91 patients were approached and 20 patients were selected for the study (online supplemental file 2). A sample size of 20 was determined based on previous qualitative studies on CKD that reached saturation. ${ }^{12} 2122$
Eleven patients refused to participate, and no patients dropped out.

\section{Data collection}

A semi-structured interview guide was used to identify the facilitators and barriers in the self-management of their disease. These questions were developed by the study team (including a nephrologist, family medicine physician and qualitative research specialist) based on the study's aims and the previous literature on this topic. ${ }^{23} 24$ The topics covered included: discovery and diagnosis of CKD, patients' awareness and knowledge, CKD's impact on patients' lives, self-management of CKD, perceived barriers and facilitators to the management of CKD, coping strategies to any challenges faced in management and suggestions for improvement. The interviews loosely adhered to the question guide, allowing interviewees to freely express their thoughts and detail their experiences while not straying too far off-topic. The question guide was pretested with the first three patients of this study, and these were included in the results. The responses from pretesting were used to modify the question guide as were considered relevant by the research team. The interviews took place at the polyclinics, either in an empty or private consult room, with only the interviewer and participant present. Each interview lasted 45 to $60 \mathrm{~min}$. All interviews were conducted face-to-face in English by clinical research coordinator (MP) who was trained in conducting in-depth interviews for qualitative research. No interviews were repeated.

Written informed consent was obtained before each interview. Patients were given and informed of the option to drop out of the study at any time. In order to maintain confidentiality and patient comfort, efforts were made to conduct interviews in a private environment. Personal identifiers were removed and data were anonymised during the analysis. Only the study ID was used to distinguish between transcripts. The names of the patients have been excluded in order to maintain anonymity.

\section{Data analysis}

Interviews were audio-recorded and transcribed verbatim by an external transcription company as well as the clinical research coordinator. Transcripts were checked by multiple researchers in the team (MP, SJH, CR, SY). They were not returned to the patients for correction. Transcripts were uploaded onto NVivo 12, a qualitative data analysis software. Both inductive and deductive strategies were used to analyse the data. Inductively, the grounded theory approach was used to ensure that the emergent themes were derived from the text. Deductively, we used the framework analysis method by employing the SEM to guide the analysis and ensure all relevant themes were identified. Transcripts and field notes taken from the interview were carefully read and coded independently by two research team members (SJH and CR). The primary coder ( $\mathrm{SJH})$ initially organised the codes based on the question guide. An initial coding scheme was created 
using line-by-line analysis and constant comparison. Transcripts were closely followed in order to maintain the original meaning of the data. When the text allowed for it, responses were grouped into multiple codes. After coding all the transcripts, similar codes were grouped together and rearranged. By grouping similar codes, emergent themes were identified which were subsequently organised into the categories of the conceptual framework. The second coder (CR) independently coded the transcripts, and the results were subsequently compared with the primary coder's analysis. Any disagreements were resolved by discussion with research team members (SJH, CR, SY, $\mathrm{THJ})$. The emergent themes were discussed among the research team and the coding scheme was revised accordingly. Transcripts were revisited multiple times to ensure all concepts were being captured. Codes and themes were refined until saturation via an iterative process until all relevant concepts of CKD management were identified.

\section{Patient and public involvement}

This research was done without patient involvement. Patients were not invited to comment on the study design and were not consulted to develop patient-relevant outcomes or interpret the results. Patients were not invited to contribute to the writing or editing of this document for readability or accuracy.

\section{RESULTS}

Table 1 outlines the demographic characteristics of the patients of this study. We interviewed 20 patients who were diagnosed with CKD who had not yet started dialysis. The majority of recruited patients had CKD stage $3{ }^{25}$ Figure 1 outlines the conceptual framework used to organise the themes that emerged from the patient interviews. It emphasises the multilayered components which affect patient's self-management of CKD and the complex interplay between individual, interpersonal and community factors. The themes have been organised under the three domains (individual, interpersonal and community/societal) of the conceptual framework and the barriers and facilitators to self-management will be described at each domain. Direct quotes are included to illustrate and elaborate on the themes. A table of all the themes, subthemes and quotes are outlined in table 2.

\section{Domain 1: Individual factors}

Barriers

\section{Lack of knowledge and awareness}

One of the most dominant themes in the entire study was the prevailing lack of knowledge and awareness of patients about the causes and symptoms of CKD. Most patients were aware that they had some problem with the kidneys but had no idea of what caused CKD or what are common symptoms that arise from having CKD. When questioned further, some patients hazarded a guess of CKD being caused by a certain diet, but almost all patients were unsure:

\begin{tabular}{lc}
\hline Table 1 Patient demographics table & \\
\hline Characteristics & Number (\%) \\
\hline Age & $67.75($ SD 4.9) \\
Gender & \\
$\quad$ Male & $14(70)$ \\
$\quad$ Female & $6(30)$ \\
Chronic kidney disease stage & \\
3 & $18(90)$ \\
4 & $2(10)$ \\
Ethnicity & \\
Chinese & $12(60)$ \\
Malay & $6(30)$ \\
Indian & $2(10)$ \\
Marital status & \\
Single & $5(25)$ \\
Married & $15(75)$ \\
Education level & \\
Primary or below & $6(30)$ \\
Secondary & $11(55)$ \\
Tertiary or above & $3(15)$ \\
Employment & \\
Unemployed & $2(10)$ \\
Employed (part-time/full-time) & $10(50)$ \\
Retired & $8(40)$ \\
\hline &
\end{tabular}

I don't really know (about CKD); people say because you take too much oil that's why your kidney is not functioning well or too sweet or salty all this sort of things. Which one to believe? (Patient 8)

Most patients had very little knowledge and awareness of CKD. For some patients, this became a motivating factor that drove them to learn more about their condition and take ownership of their management. For others, this lack of knowledge had a detrimental effect on their self-management and perceived control of the disease.

\section{Fatalistic thinking leading to lack of motivation}

Another common factor that influenced patient's selfmanagement was their level of discipline and motivation. For example, many patients adopted a fatalistic attitude with regard to their condition, which inevitably led to apathy:

I ask for myself, I come to this stage what else can I do? I only depend on the medication; I only depend on what the results? Furthermore, I cannot do anything much, because it is an organ inside me, it is not mechanical where I can replace. So I just have to. (Patient 11)

This kind of fatalistic thinking often times led some patients to doubt the efficacy of treatment. It also fueled the feeling of helplessness: 


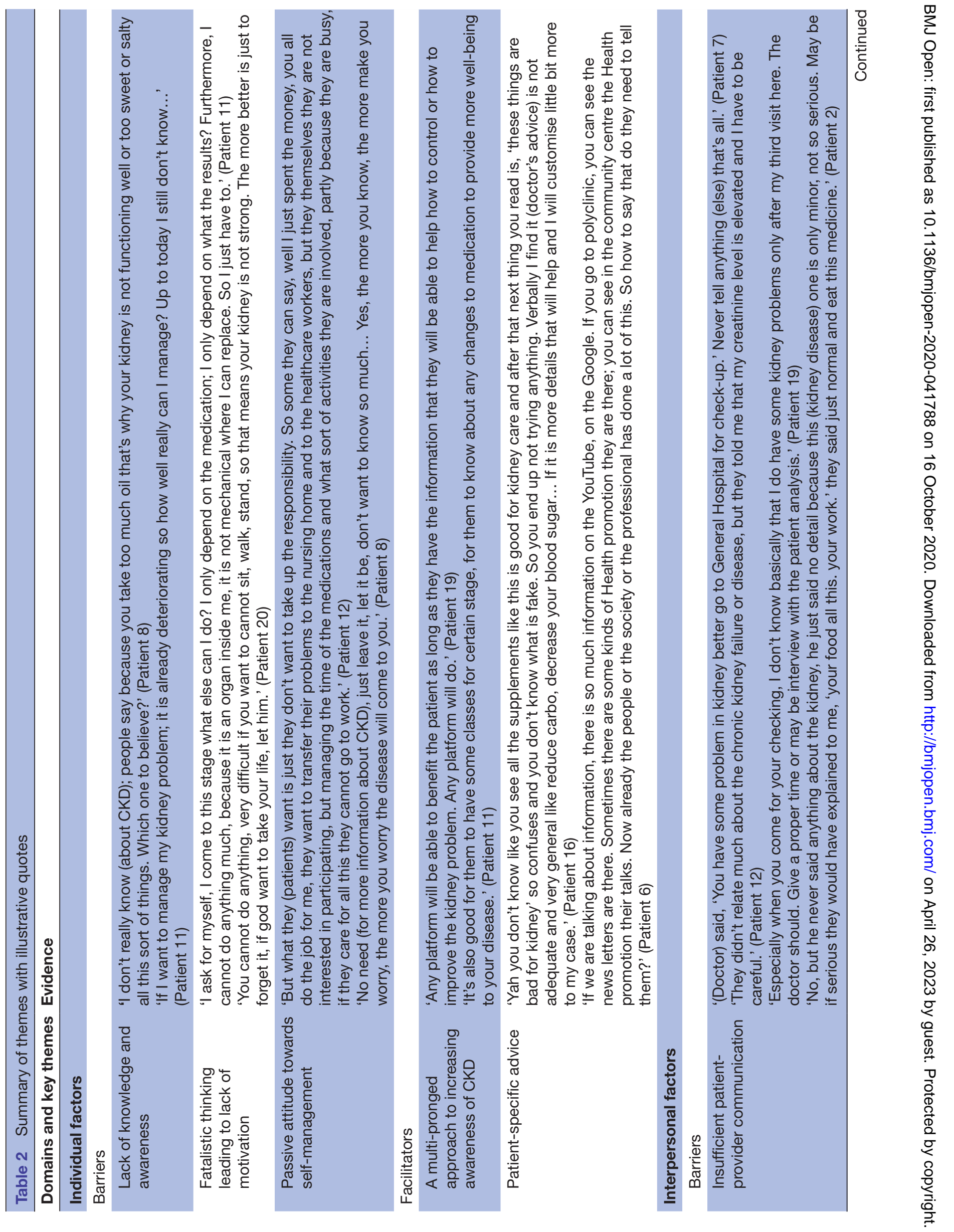




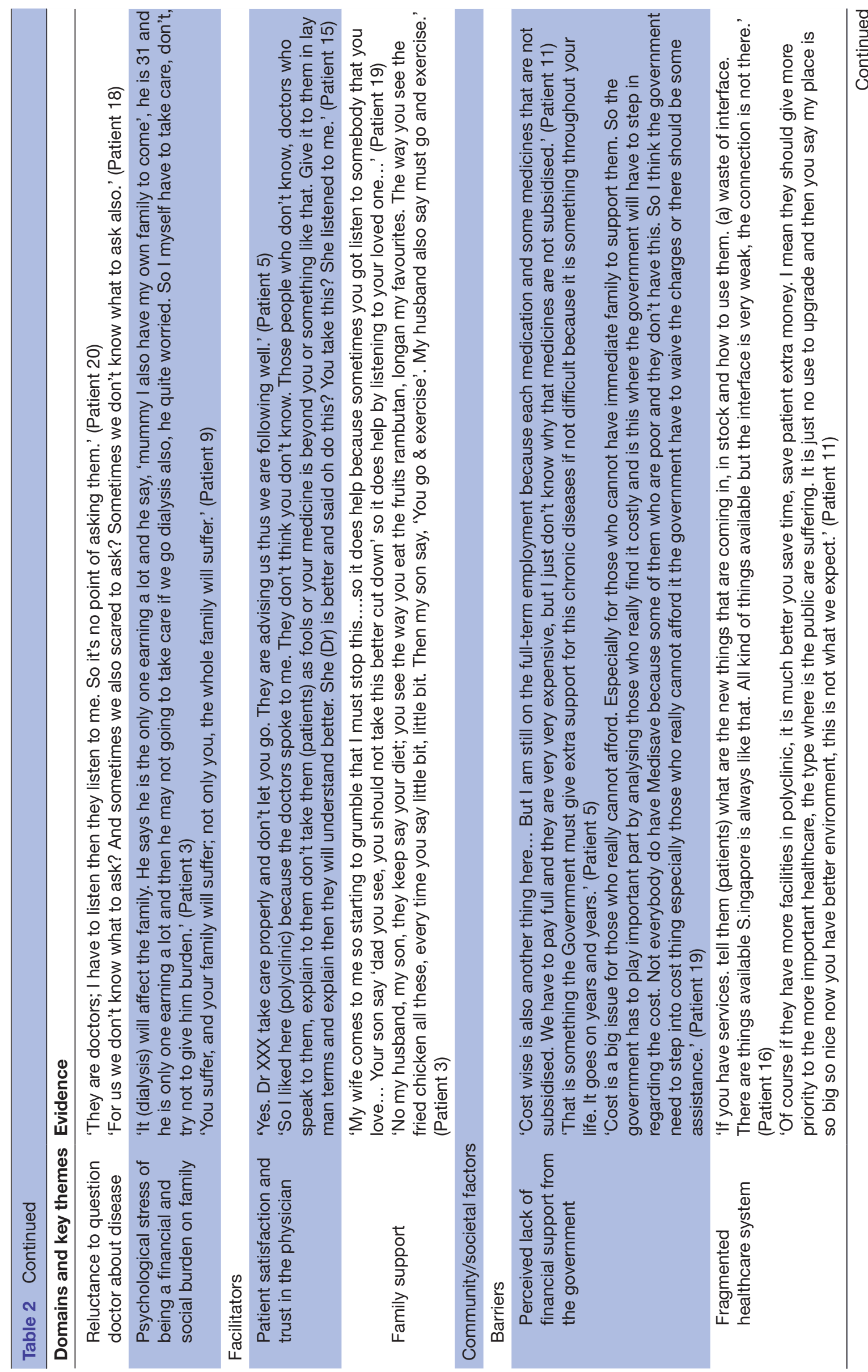




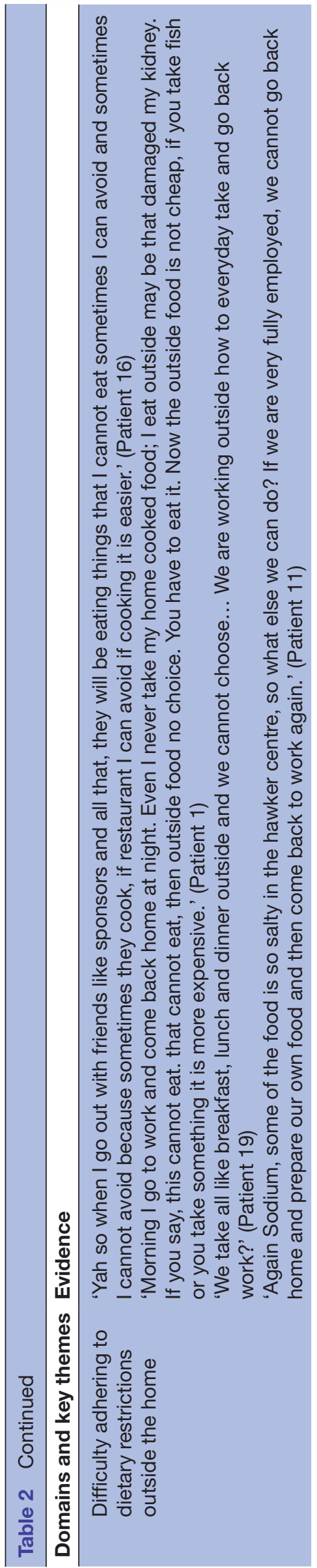

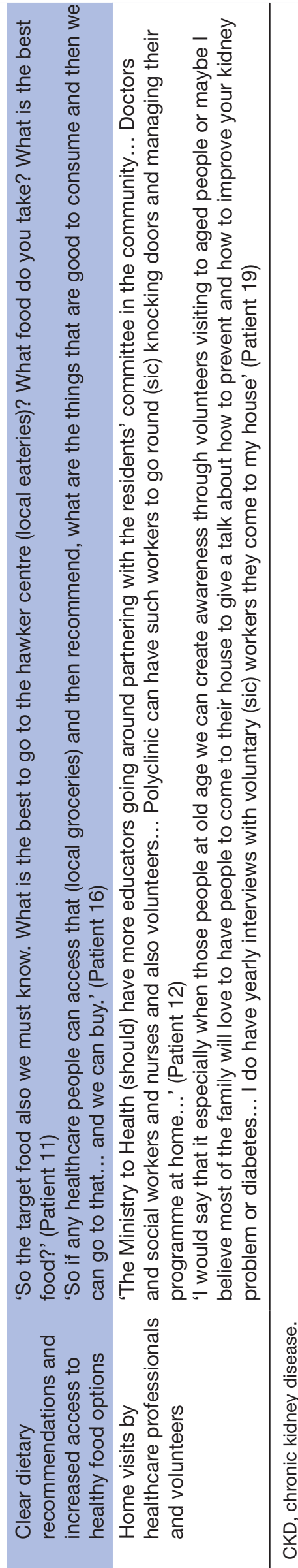


Some people have that kind of mindset you know this thing is already defeated so there is nothing much I can do. Even what I do also I cannot make it better... (Patient 10)

Many patients did not see or believe in the benefits of actively managing one's own disease, and even if they did, patients often found it difficult to incorporate management regimes such as following dietary recommendations and exercise into their busy schedules.

\section{Passive attitude towards self-management}

Patients' sense of responsibility for their own health was another significant factor in self-management. Many patients adopted a passive attitude, delegating the responsibility of care on others. For example, one patient, speaking on behalf of fellow patients, mentioned that they expect healthcare workers to do everything for them, and that patients don't want the extra burden of responsibility:

But what they (patients) want is just they don't want to take up the responsibility. So some they can say, well I just spent the money, you all do the job for me, they want to transfer their problems to the nursing home and to the healthcare workers, but they themselves they are not interested in participating, but managing the time of the medications and what sort of activities they are involved, partly because they are busy, if they care for all this they cannot go to work. (Patient 12)

Conversely, there were patients who understood that they had to actively participate in their own care:

It works in two ways; you have to connect with the healthcare also. No point the healthcare has to look after you; it is your personal health... In home it's your duty to look after yourself. (Patient 17)

These patients were often self-motivated, gathering information about their disease and took ownership of their care. Whereas some patients were content with their ignorance, these patients took initiative to educate themselves and improve their self-management.

\section{Facilitators (Individual)}

\section{A multi-pronged approach to increasing awareness of CKD}

Lack of awareness and knowledge of CKD was one of the most dominant themes in the study, and therefore the most common suggestion for improvement of CKD management was for more information regarding CKD. However, practical suggestions on how to do this were diverse: some wanted information directly from the healthcare providers, and others wanted information in booklet form or even via email. Other patients asked for an interactive session where they could freely ask questions about CKD, and some patients asked for home visits by healthcare providers. These diverse responses suggest that information should be disseminated using a variety of media.
Any platform (for information) will be able to benefit the patient as long as they have the information that they will be able to help how to control or how to improve the kidney problem. Any platform will do. (Patient 19)

\section{Patient-specific advice}

Many patients expressed that they received all kinds of advice about CKD from many different sources. As a result, some patients were at a loss as to what information to follow. One patient, when asked if lack of information contributed to poor adherence to treatment, commented that there was a plethora of information available:

If we are talking about information, there is so much information on the YouTube, on the Google. If you go to polyclinic, you can see the news letters are there... You can see in the community centre the Health promotion their talks. Now already the people or the society or the professional has done a lot of this. So how to say that do they need to tell them? (Patient 6)

Another patient commented that instead of generic advice they would prefer to have personalised information specific to the patient and his/her condition.

Like you see all the supplements like this is good for kidney care and after that next thing you read is, 'these things are bad for kidney' so confuses (sic) and you don't know what is fake. So you end up not trying anything. Verbally I find it (doctor's advice) is not adequate and very general like reduce carbo, decrease your blood sugar. If it is more details that will help and I will customise little bit more to my case. (Patient 16)

\section{Domain 2: Interpersonal factors}

Barriers Insufficient communication between doctor and patient

A recurring theme regarding the patient-physician relationship was the lack of communication, both in quality and quantity. This was especially evident in the disclosure of the CKD diagnosis, which most patients described as very brief and at times ambiguous. One patient recalled how he received his diagnosis:

(Doctor) said, 'You have some problem in kidney better go to General Hospital for check-up... Never tell anything (else) that's all. (Patient 7)

Another patient did not find out about his diagnosis until much later on and expressed that he would have liked his doctor to take the time to clearly explain the diagnosis to him.

Especially when you come for your checking, I don't know basically that I do have some kidney problems only after my third visit here. The doctor should... give a proper time or may be interview with the patient analysis. (Patient 19) 


\section{Reluctance to question doctor about disease}

The doctors were not the only ones to blame for the lack of communication, however, because many patients admitted that they seldom ask questions about their condition. When probed about the reason for this reluctance to ask questions, one patient replied succinctly:

They are doctors; I have to listen, then they listen to me. So it's no point of asking them. (Patient 20)

This reluctance highlights the asymmetric relationship between patient and physician. Although the patients may want to know more about their condition, many expressed that they felt reluctant to speak up and question the doctor.

\section{Psychological stress of being a financial and social burden on the family}

Apart from the patient-physician relationship, family played a huge role in helping patients manage their disease. Many patients relied heavily on their family to support them both financially and emotionally. However, one negative aspect of this dependence on family was the self-inflicted pressure to not burden family. One patient looking ahead to possible dialysis explained that she didn't want to burden her son who has a family of his own to support:

It (dialysis) will affect the family. He (Son) says he is the only one earning a lot and he say, 'mummy I also have my own family to come', he is 31 and he is only one earning a lot and then he may not going to take care if we go dialysis also, he quite worried. So I myself have to take care. Try not to give him burden. (Patient 3)

This pattern of thinking was evident in many patients and it led to unnecessary pressure and burden on them. Instead of reaching out to family members for help, they felt solely responsible for managing their condition.

\section{Facilitators (Interpersonal)}

\section{Family support}

For most patients however, family was an indispensable resource in managing their condition. Family members reminded patients to take their medicine, adhere to dietary restrictions and to maintain an active lifestyle. One patient described how his family helped him:

(My) son say 'dad you see, you should not take this, better cut down' so it does help by listening to your loved one... (Patient 19)

Many patients expressed that family was an important consideration in the management of their condition. Family support was an invaluable motivating factor in taking care of their health.

\section{Patient satisfaction and trust in physician}

Some patients in the study who enjoyed a close relationship with their doctors were satisfied with the level of communication between them. Subsequently, these patients who trusted their doctors felt more motivated to follow their advice. One patient mentioned that he/ she really appreciates his/her current doctor because she communicates clearly and humbly:

So I liked here because the doctors spoke to me. They don't think you don't know. Those people who don't know, doctors who speak to them, explain to them don't take (patients) as fools or your medicine is beyond you or something like that. Give it to them in lay man terms and explain then they will understand better. She (Dr) is better and said oh do this? You take this? She listened to me. (Patient 15)

\section{Domain 3: Community and societal factors \\ Barriers \\ Perceived lack of financial support from the government}

Most patients expressed that they had financial difficulties in meeting all the expenses incurred from treatment (medications, investigations, consultation fees). Although no specific medications were mentioned by name, most patients had comorbidities and complained of polypharmacy. One patient said that the high cost of all his medications and the lack of government subsidies was a challenge:

Cost wise is also another thing here... But I am still on the full-term employment because each medication and some medicines that are not subsidised. We have to pay full and they are very very expensive, but I just don't know why that medicines are not subsidised. (Patient 11)

\section{Fragmented healthcare system}

Some patients saw a need for a more integrated healthcare system that provided continuity of care and a more efficient referral process. One patient lamented that due to a lack in continuity of care, there was no direction or guidance in choosing what would be most beneficial to him.

If you have services. Tell them (patients) what are the new things that are coming in, in stock and how to use them. (a) waste of interface. There are things available. Singapore is always like that. All kind of things available but the interface is very weak, the connection is not there. (Patient 16)

In short, patients in our study saw a need for a "userfriendly' healthcare system that was easy to navigate and access.

\section{Difficulty adhering to dietary restrictions outside the home}

Many patients found it very difficult to adhere to their dietary restrictions, especially when their schedule required them to eat a good number of their meals outside the home. One patient found it difficult to find 
food in hawker centres (local food eateries in Singapore) that aligned to his diet:

Again Sodium, some of the food is so salty in the hawker centre, so what else we can do? If we are very fully employed, we cannot go back home and prepare our own food and then come back to work again. (Patient 11)

Many patients found that their busy work schedules and limited options at food services outside of the home made it challenging for them to adhere to a healthy diet.

\section{Facilitators (Community and society) \\ Clear dietary recommendations and increased access to healthy food options}

Not surprisingly then, many patients commented that they need clear recommendations regarding their diet. Their suggestion was twofold: tell us what to eat and make it available in the local groceries and food courts.

So the target food also we must know. What is the best to go to the hawker centre (local eateries)? What food do you take? What is the best food? (Patient 11)

\section{Home visits by healthcare professionals and volunteers}

Many patients expressed that they need greater guidance and support from healthcare professionals on how to manage their disease. One of these patients suggested that healthcare professionals or volunteers visit patients at home for patient education and monitoring:

I would say that it especially when those people at old age we can create awareness through volunteers visiting to aged people or maybe I believe most of the family will love to have people to come to their house to give a talk about how to prevent and how to improve your kidney problem or diabetes... I do have yearly interviews with voluntary (sic) workers they come to my house. (Patient 19)

\section{DISCUSSION}

This qualitative study identified the primary individual, interpersonal and community factors that contribute to the self-management of patients with CKD. Addressing these barriers could potentially decelerate the progression of CKD to ESKD among patients, reduce healthcare expenditure on renal replacement therapy and bolster the current standard of care by empowering patients' selfmanagement skills.

Although most patients lacked awareness of CKD and wanted more information, many said that there was actually an overload of written and online information. This finding aligns with studies which suggest that a unique challenge of healthcare in the digital age is the overload of potentially irrelevant information that patients can find online about their condition. ${ }^{26}$ This was especially evident in our study with regard to dietary recommendations, as patients felt there was too much noise and too little guidance for patients. To combat this confusion, clear dietary guidelines that cover the local food options should be provided by the polyclinics and communicated to patients with CKD.

A common barrier to self-management was the lack of communication between patient and physician, which corresponded with findings from multiple studies. ${ }^{27-30}$ One of these studies found that such communication tended to be short, revolved around laboratory values and full of jargon. ${ }^{9}$ This lack of effective communication is compounded by patients' reluctance to query their doctors about their condition. Other studies also alluded to patients' sentiments that 'doctors know best' and their inertia speak up about their care. ${ }^{31-33}$ Conversely, effective communication with doctors who expressed care and concern for patients was found to be a major facilitator to self-management.

Another factor that significantly contributed to patients' self-management was their level of ownership and responsibility for their condition. Patients who had a high level of ownership typically were self-motivated to learn about and manage their disease while patients with a low level of ownership were indifferent about their treatment. This was consistent with previous research that named these two groups of patients 'passive receivers' and 'active engagers. ${ }^{3455}$ The 'receivers' in our study often delegated the responsibility of their care to another party-typically to healthcare professionals or to their family members. This passive attitude to care may also reflect the lack of a shared decision-making culture in local clinical practice. Additionally, many of these 'receivers' had a fatalistic outlook on their condition and felt that self-management was pointless. Studies have shown that a combination of patient, provider and organisational strategies are required to increase patient engagement. ${ }^{36}$ These strategies include increasing patient access by providing telehealth appointments and improving care by coordinating with allied health professionals to provide sufficient patient education. ${ }^{9}$

This study also found that family had a vital role to play in facilitating the self-management of patients. This finding was similar to other qualitative studies done in Singapore and the USA. ${ }^{23} 3738$ However, our study, as well as the other studies in Singapore and Asia, ${ }^{23} 39$ patients worried about being a financial and social burden on the family. This difference may be due to a number of factors including the Asian culture of collectivism, in which people primarily see themselves in the context of family and society, as opposed to individualism in the West. ${ }^{40}$ However, it could also reflect differences due to the financial reimbursement of CKD. In many countries in the West, ESKD care is primarily funded by the government, whereas in Singapore and other Asian countries, a significant proportion of the cost is borne by patients and their families. Another difference between Singapore and the West is that families are more likely to live with their elderly parents. In this context, strong family 
support likely plays a more prominent role in the selfmanagement of these patients.

Given the lack of awareness of CKD among patients and the lack of patient-physician communication, there may be a need for a 'health coach' who is available to spend extended time with patients. A study on patients with chronic disease in Finland found that health coaching significantly improved the physiological and psychological outcomes of patients, including an increase in physical activity, weight loss, improvement of HbAlc (glycatedhaemoglobin) levels. ${ }^{35}$ Another study in America found that 'health coaches' (trained volunteers from the community) reduced hospitalisation rates and emergency department use among patients with chronic diseases. ${ }^{13}$ A potential avenue this coaching could take place is through telehealth monitoring. Several patients in this study requested for online information and resources to improve CKD management. However, the effectiveness of the telemonitoring approach for CKD remains to be evaluated.

A multi-pronged approach is required to address these barriers and improve CKD care. Uncovering these facilitators and barriers will lay the groundwork for the development of strategies that improve the self-management of CKD, leading to improved patient outcomes.

\section{Strengths and limitations}

This is likely to be the first qualitative study to explore the barriers and facilitators to early CKD management from the patients' perspective in Singapore. We used both inductive and deductive methods to effectively capture all the key themes from the patient interviews. Using the social-ecological model as our conceptual framework gave us a holistic view of the barriers and facilitators to CKD care.

This qualitative study has some limitations. Although we used a purposive sampling approach, many female patients declined to participate which led to an imbalance in the gender distribution. Only patients with diabetes were included in the study, so the perspective of CKD patients without diabetes is not explored. We did not collect information on how long patients have had CKD. Also, only English-speaking patients were recruited, which meant that the perspectives of patients who only speak Chinese or Malay (or not fluent in English) were not directly represented in this study. Since these patients are usually of a lower socio-economic status, the perspectives of those most disadvantaged in CKD self-management may not have been fully explored. Furthermore, the interviews were conducted in English, which was not the primary language for many patients who participated. The multicultural backgrounds of the patients in this study may also have led to cultural references and subtleties in meaning to be lost in the analysis process. To combat this issue, researchers received prior training on performing in-depth interviews for qualitative studies in order to minimise bias and to preserve the original meaning of the interviews. Finally, patients were not involved in the design and interpretation of this study.

\section{CONCLUSION}

This study found that a lack of knowledge and awareness of CKD among patients, a passive attitude toward selfmanagement and insufficient communication between doctor and patient to be key barriers to the management of predialysis CKD in the primary care setting in Singapore. We also found that strong interpersonal relationships with doctors and family members were main facilitators to self-management in these patients. In order to address these issues, there needs to be a greater emphasis on patient-centred communication and therapeutic alliance, as many patients often feel inundated with information from various sources. Optimisation of family support and clear communication of dietary recommendations will also further equip patients to manage their own condition.

\section{Twitter Tazeen H Jafar @COBRAStudy}

Acknowledgements The authors would like to thank Ms Patricia T. Kin and Ms Caris Yang Thong Tan from the Department of Research in SingHealth Polyclinics.

Contributors THJ conceived the study and designed it in collaboration with NCT. SG, JYL and ZYC facilitated the patient recruitment and data collection process. MP conducted and transcribed the interviews. SJH and CR coded the data, and SY reviewed the codes. Initial drafts of the manuscript were written by SJH, which were reviewed and edited by THJ and SY. All authors contributed to analysis and interpretation and also read and approved the final manuscript.

Funding The research was supported by research funding received from SingHealth Duke-NUS Health Services Research Institute (HSRI). THJ is supported by the National Medical Research Council (NMRC), Singapore. The grant numbers are SHF/HSR101/2016 and NMRC/CSA-SI/0005/2015, respectively. The funding bodies played no role in the design of the study and collection, analysis and interpretation of data and in writing manuscript.

Competing interests None declared.

Patient consent for publication Not required.

Ethics approval The SingHealth Centralized Institutional Review Board granted ethics approval. Ethics approval number: 2017/2108.

Provenance and peer review Not commissioned; externally peer reviewed.

Data availability statement Data are available upon reasonable request. Data are available on reasonable request from the corresponding author subject to approval by the IRB.

Open access This is an open access article distributed in accordance with the Creative Commons Attribution Non Commercial (CC BY-NC 4.0) license, which permits others to distribute, remix, adapt, build upon this work non-commercially, and license their derivative works on different terms, provided the original work is properly cited, appropriate credit is given, any changes made indicated, and the use is non-commercial. See: http://creativecommons.org/licenses/by-nc/4.0/.

\section{ORCID iDs}

Ngiap Chuan Tan http://orcid.org/0000-0002-5946-1149

Tazeen H Jafar http://orcid.org/0000-0001-7454-8376

\section{REFERENCES}

1 Jha V, Garcia-Garcia G, Iseki K, et al. Chronic kidney disease: global dimension and perspectives. Lancet 2013;382:260-72.

2 Gansevoort RT, Correa-Rotter R, Hemmelgarn BR, et al. Chronic kidney disease and cardiovascular risk: epidemiology, mechanisms, and prevention. The Lancet 2013;382:339-52. 
3 Webster AC, Nagler EV, Morton RL, et al. Chronic kidney disease. Lancet 2017;389:1238-52.

4 Eriksson JK, Neovius M, Jacobson SH, et al. Healthcare costs in chronic kidney disease and renal replacement therapy: a populationbased cohort study in Sweden. BMJ Open 2016;6:e012062.

5 US Renal Disease Systems. 2015 USRDS annual data report: epidemiology of kidney disease in the United States. Bethesda, MD: National Institutes of Health, National Institute of Diabetes and Digestive and Kidney Diseases, 2015.

6 Singapore renal registry annual report 2017. Singapore National Registry of Diseases; 2019. https://www.nrdo.gov.sg/docs/ librariesprovider3/publications-kidney-failure/srr-annual-report-2017. pdf?sfvrsn=ec303a7c_0

7 Assadi F. The growing epidemic of chronic kidney disease: preventive strategies to delay the risk for progression to esrd. In: Kelishadi R, ed. Primordial prevention of non communicable disease. Cham: Springer International Publishing, 2019: 57-9.

8 Lin C-C, Tsai F-M, Lin H-S, et al. Effects of a self-management program on patients with early-stage chronic kidney disease: a pilot study. Applied Nursing Research 2013;26:151-6.

9 Agha A, Werner R, Keddem S, et al. Improving patient-centered care: how clinical staff overcome barriers to patient engagement at the vha. Medical Care 2018;56:1009-17.

10 Roberti J, Cummings A, Myall M, et al. Work of being an adult patient with chronic kidney disease: a systematic review of qualitative studies. BMJ Open 2018;8:e023507.

11 Jafar TH, Ramakrishnan C, John O, et al. Access to CKD care in rura communities of India: a qualitative study exploring the barriers and potential facilitators. BMC Nephrol 2020;21:26

12 Griva $\mathrm{K}, \mathrm{Ng} \mathrm{HJ}$, Loei J, et al. Managing treatment for end-stage renal disease - a qualitative study exploring cultural perspectives on facilitators and barriers to treatment adherence. Psychol Health 2013;28:13-29.

13 Dye C, Willoughby D, Aybar-Damali B, et al. Improving chronic disease self-management by older home health patients through community health coaching. Int J Environ Res Public Health 2018;15:660.

14 Richard AA, Shea K. Delineation of self-care and associated concepts: self-care concept delineation. J Nurs Scholarsh 2011;43:255-64.

15 Lin M-Y, Liu MF, Hsu L-F, et al. Effects of self-management on chronic kidney disease: a meta-analysis. Int J Nurs Stud 2017;74:128-37.

16 Morton RL, Tong A, Howard K, et al. The views of patients and carers in treatment decision making for chronic kidney disease: systematic review and thematic synthesis of qualitative studies. BMJ 2010;340:c112.

17 McLeroy KR, Bibeau D, Steckler A, et al. An ecological perspective on health promotion programs. Health Educ Q 1988;15:351-77.

18 Dao J, Spooner C, Lo W, et al. Factors influencing self-management in patients with type 2 diabetes in general practice: a qualitative study. Aust J Prim Health 2019;25:176-84.

19 Clark KA, Keene DE, Pachankis JE, et al. A qualitative analysis of multi-level barriers to HIV testing among women in Lebanon. Cult Health Sex 2017;19:996-1010.

20 Dunn RL, Kalich KA, Henning MJ, et al. Engaging field-based professionals in a qualitative assessment of barriers and positive contributors to breastfeeding using the social ecological model. Matern Child Health J 2015;19:6-16.
21 Han E, Haldane V, Koh JJK, et al. Perspectives on decision making amongst older people with end-stage renal disease and caregivers in Singapore: a qualitative study. Health Expect 2019;22:1100-10.

22 Moser A, Korstiens I. Series: practical guidance to qualitative research. Part 3: sampling, data collection and analysis. Eur J Gen Pract 2018;24:9-18.

23 Shirazian S, Crnosija N, Weinger $\mathrm{K}$, et al. The self-management experience of patients with type 2 diabetes and chronic kidney disease: a qualitative study. Chronic IIIn 2016;12:18-28.

24 Tong A, Sainsbury P, Chadban S, et al. Patients' experiences and perspectives of living with CKD. Am J Kidney Dis 2009;53:689-700.

25 Coresh J, Selvin E, Stevens LA, et al. Prevalence of chronic kidney disease in the United States. JAMA 2007;298:2038-47.

26 Klerings I, Weinhandl AS, Thaler KJ. Information overload in healthcare: too much of a good thing? Z Evid Fortbild Qual Gesundhwes 2015;109:285-90.

27 Greer RC, Crews DC, Boulware LE. Challenges perceived by primary care providers to educating patients about chronic kidney disease. $J$ Ren Care 2012;38:174-81.

28 Greer RC, Cooper LA, Crews DC, et al. Quality of patient-physician discussions about CKD in primary care: a cross-sectional study. $A m$ J Kidney Dis 2011;57:583-91.

29 Junaid Nazar CM, Kindratt TB, Ahmad SMA, et al. Barriers to the successful practice of chronic kidney diseases at the primary health care level; a systematic review. J Renal Inj Prev 2014;3:61-7.

30 Mechta Nielsen T, Frøjk Juhl M, Feldt-Rasmussen B, et al. Adherence to medication in patients with chronic kidney disease: a systematic review of qualitative research. Clin Kidney $J$ 2018:11:513-27.

31 Costantini L, Beanlands H, McCay E, et al. The self-management experience of people with mild to moderate chronic kidney disease. Nephrol Nurs J 2008;35:147-55

32 Pilnick A, Dingwall R. On the remarkable persistence of asymmetry in doctor/patient interaction: a critical review. Soc Sci Med 2011;72:1374-82.

33 Bonner A, Lloyd A. Exploring the information practices of people with end-stage kidney disease. J Ren Care 2012;38:124-30.

34 Havas K, Douglas C, Bonner A. Person-centred care in chronic kidney disease: a cross-sectional study of patients' desires for selfmanagement support. BMC Nephrol 2017;18.

35 Kivelä K, Elo S, Kyngäs $\mathrm{H}$, et al. The effects of health coaching on adult patients with chronic diseases: a systematic review. Patient Educ Couns 2014;97:147-57.

36 McCormack L, Thomas V, Lewis MA, et al. Improving low health literacy and patient engagement: a social ecological approach. Patient Educ Couns 2017;100:8-13.

37 Han E, Shiraz F, Haldane V, et al. Biopsychosocial experiences and coping strategies of elderly ESRD patients: a qualitative study to inform the development of more holistic and person-centred health services in Singapore. BMC Public Health 2019;19:1107.

38 Strom JL, Egede LE. The impact of social support on outcomes in adult patients with type 2 diabetes: a systematic review. Curr Diab Rep 2012:12:769-81.

39 Sohal T, Sohal P, King-Shier KM, et al. Barriers and facilitators for type-2 diabetes management in South Asians: a systematic review. PLoS One 2015;10:e0136202.

40 Ingersoll-Dayton B, Saengtienchai C, Kespichayawattana J, et al. Measuring psychological well-being: insights from Thai elders. Gerontologist 2004;44:596-604. 